\title{
Counseling in Pediatric Audiology: Audiologists' Perceptions, Confidence, and Training
}

DOI: $10.3766 /$ jaaa. 17087

\author{
Karen Muñoz*† \\ Tanner Price* \\ Lauri Nelson* \\ Michael Twohig;
}

\begin{abstract}
Background: Pediatric audiologists are an important source of support for parents when a child is identified with hearing loss. As parents learn how to manage their child's hearing loss they often need help navigating challenges that arise; however, audiologists may experience a variety of barriers implementing effective counseling strategies. Many internal and external barriers experienced by parents can be appropriately supported and navigated within audiology services.
\end{abstract}

Purpose: To investigate audiologists' perceptions, training, and confidence related to counseling and to explore the influence of years practicing audiology and taking a counseling course on perceptions and confidence.

Research Design: A cross-sectional, population-based survey.

Study Sample: Three hundred and fifty surveys were analyzed from pediatric audiologists across the U.S. Responses were received from 26 states and one U.S. territory.

Data Collection and Analysis: Data were collected through the mail and online. Descriptive and comparative statistics were used to analyze the information. Content analysis was performed to identify emergent themes from the responses to open-ended questions.

Results: Pediatric audiologists reported their perceptions about importance of counseling skills, challenges they encounter, their confidence in counseling, and how often they use the skills when needed in practice. Most audiologists $(\geq 75 \%)$ felt it was very or extremely important to talk with parents about nine of the ten items (e.g., their [parents'] expectations). Three-fourth of the audiologists reported experiencing a moderate challenge or greater in knowing how to assess the presence of psychosocial challenges and in having enough time to address emotional needs. Many of the audiologists felt very or extremely confident in guiding parents in the development of an action plan (62\%) and determining if parents have external barriers (60\%). Approximately one-third or less of the participants reported performing any of the skills (e.g., determining if parent has external or internal barriers) $\geq 75 \%$ of the time, and a statistically significant difference was found with participants practicing $\leq 10 \mathrm{yr}$ using the skills more frequently than participants practicing for $\geq 11 \mathrm{yr}$. In addition, there was a statistically significant difference between participants who had taken an audiology-specific counseling course and those who had not; those who had reported being more confident and using counseling skills more often than audiologists did not have a counseling course.

Conclusions: This study found strong support for audiologist perceived importance of counseling; however, fewer audiologists reported confidence in their counseling skills and in using counseling skills. Counseling training was variable; audiologists would benefit from a more systematic approach to counseling instruction within graduate training.

Key Words: confidence, counseling, pediatric audiology

*Department of Communicative Disorders and Deaf Education, Utah State University, Logan, UT; †National Center for Hearing Assessment and Management, Utah State University, Logan, UT; †Department of Psychology, Utah State University, Logan, UT

Corresponding author: Karen Muñoz, 2620 Old Main Hill, Logan, UT 84322; Email: Karen.munoz@usu.edu 
$\mathrm{D}$ evelopmental outcomes for children who are deaf or hard of hearing can be optimized when they receive appropriate and timely intervention (Tomblin et al, 2015). Audiologists not only provide technical expertise and services but, through counseling, also address emotional adjustment and related psychosocial challenges to help parents with acceptance, adaptation, and skill acquisition necessary for effectively managing their child's hearing loss (ASHA, 2008; AAA, 2013). Early hearing loss identification and appropriate amplification is critical for maximizing spoken language development. Parents, however, can encounter a multitude of challenges that interfere with hearing aid use, such as gaining confidence with new skills, managing difficult child behavior (e.g., removing hearing aids), and fear about how others may react to their child (Walker et al, 2013; Muñoz et al, 2015; 2016). Targeted support from their audiologist to purposefully address parents' needs can increase hours of hearing aid use (Muñoz, Kibbe, et al, 2017).

Through positive audiologist-parent partnerships, audiologists can help parents of pediatric patients recognize barriers to intervention and identify effective solutions. Barriers can arise from multiple sources. Many parents are unfamiliar with hearing loss and lack knowledge about hearing related issues, or they may experience difficulty paying for hearing technology. Barriers, such as needing information or finding resources are external barriers. Parents may also experience denial about the hearing loss, feel sad, or lack confidence about how to check the hearing aids. Barriers related to emotions, thoughts, or feelings are internal barriers. To be effective in helping parents, audiologists need to counsel each family according to their unique needs by assessing for and addressing external and internal barriers that are interfering with the intervention process. Patientcentered care is built on a trusting relationship between the patient and provider, and when service delivery embraces this relationship, increased shared decisionmaking and adherence to implementation strategies lead to improved patient-reported outcomes (IOM, 2001).

Services provided from a biopsychosocial orientation are grounded in the importance of considering the whole person, not only the presenting problem, in assessing and addressing client needs (Clark and English, 2014). Evidence-based counseling can be infused in audiology service delivery at the time of diagnosis, during adaptation to intervention, and in supporting maintenance and future growth through intentional interviewing (Ivey et al, 2016). When microskills (e.g., open questions, active listening, and validation) are appropriately and effectively implemented, audiologists can help clients achieve their goals. When clients' psychosocial challenges extend beyond the scope of audiology services, partnering with mental health professionals can bridge support for addressing more complex client challenges (Stone and Olswang, 1989).
Recent research in audiology has explored audiologistpatient communication, and opportunities for improvement have been observed. For example, audiologists infrequently assessed and addressed patients' emotional concerns during hearing device monitoring appointments (Muñoz, Ong, et al, 2017). In appointments with older adults, audiologists responded to patients' psychosocial concerns with technical information (Grenness et al, 2015b), and during history taking, audiologists took control of the exchange by asking closed questions, and frequently interrupted the client, resulting in verbal dominance by the audiologist (Grenness et al, 2015a). Furthermore, when emotional concerns were not adequately addressed, the patient continued to raise the concern (Ekberg et al, 2014).

Audiologists may experience a variety of barriers implementing counseling strategies that address patient adjustment and psychosocial challenges. Audiologists have reported that there is not enough time to address client emotions during appointments (Meibos et al, 2016); although, Stewart et al (1989) found that patient-centered interviewing only increased the duration of the conversation on average by one minute. Audiologists have also reported feeling uncertain about how to respond when clients expressed psychosocial concerns (Muñoz, Ong, et al, 2017) and have expressed a desire for more training in counseling (Meibos et al, 2016).

Even though audiology practice guidelines include counseling patients (AAA, 2004; ASHA, 2008), certification competencies for graduate student training (ASHA, 2012) provide minimal guidance. It is reasonable to assume that the counseling training audiologists receive will influence their level of confidence and their counseling behaviors when interacting with patients. The extent to which graduate training programs are preparing future audiologists for the counseling aspect of practice is unclear. It is clear, however, that audiologists will encounter clients who are struggling with a range of barriers coping with hearing loss for which evidence-based counseling strategies can be intentionally incorporated to improve adherence to treatment recommendations and intervention outcomes.

Pediatric audiologists have an opportunity, and in fact, an ethical responsibility, to support parent engagement in behaviors that can improve their child's communication outcomes and quality of life. There is scarce evidence related to counseling competence in current audiological services. The research that is available suggests training and practice gaps exist. The purpose of the present study was to investigate pediatric audiologists' perceptions, training, and confidence related to counseling. A secondary purpose was to explore the influence of years of practicing audiology and taking a counseling course during graduate training have on perceptions and confidence related to counseling. 


\section{METHOD}

A cross-sectional survey design was used to sample practicing pediatric audiologists. Institutional Review Board approval was obtained before data collection. Responses to the questionnaire were anonymous.

\section{Participants and Procedures}

Practicing pediatric audiologists were recruited to complete the survey through state Early Hearing Detection and Intervention programs. State and territory Early Hearing Detection and Intervention coordinators were sent an e-mail asking for assistance in obtaining a current list of pediatric audiologists, and 26 states and one U.S. territory agreed to either provide the mailing list or to mail the surveys to the audiologists in their state. In two states, the list included all licensed audiologists. Audiologists were sent a flyer describing the study, Institutional Review Board letter of information, survey, and a prepaid envelope to return the survey. The survey was also available electronically through a link provided on the paper survey. A reminder postcard was mailed two weeks after the survey was sent and included the link to complete the survey online.

Surveys were distributed to 2,127 audiologists in October 2016. Of those, 156 were returned as undeliverable by the postal service, resulting in delivery of 1,971 surveys. Completed surveys were received from 363 pediatric audiologists in 26 states and one U.S. territory, for an overall response rate of $18 \%$. Two states sent surveys to all audiologists in their state $(n=817)$; completed surveys from those states resulted in a 7\% $(\mathrm{n}=54)$ response rate. The remaining states sent a targeted mailing to pediatric audiologists $(\mathrm{n}=1154)$; completed surveys from those states resulted in a $27 \%$ return rate $(\mathrm{n}=309)$. Thirteen surveys were excluded from the analysis because the respondent did not provide pediatric audiology services in the three mo $(n=10)$ before completing the survey or the returned survey was incomplete $(\mathrm{n}=3)$. Surveys were analyzed for 350 pediatric audiologists (see Table 1 for demographic information).

\section{Instrument}

The survey instrument was developed by the authors. Before distributing the survey, two steps were taken to refine the survey content. First, a panel of four audiologists with content expertise in counseling reviewed the instrument and provided feedback for face validity. Second, pediatric audiologists in Utah were invited to complete a pilot survey; 26 pediatric audiologists completed the online survey. Through this process, modifications were made before distribution of the survey, including rewording questions to improve clarity, removing redun-
Table 1. Participant Demographic Information

\begin{tabular}{lcc}
\hline Participants (N $=350)$ & $\%(n)$ & $M(S D)$ \\
\hline Gender & $92(318)$ & \\
$\quad$ Female & $8(27)$ & \\
$\quad$ Male & $<1(1)$ & $43(11.04)$ \\
$\quad$ Prefer not to answer & & $17(11.33)$ \\
Age in years & $38(133)$ & \\
Years practicing audiology & $62(214)$ \\
$\quad \leq 10$ & \\
$\quad \geq 11$ & $24(86)$ \\
Percentage of pediatric services & $34(118)$ \\
during previous three mo & $42(145)$ \\
$\quad<25 \%$ & \\
$25-50 \%$ & $91(315)$ \\
$>75 \%$ & $5(16)$ \\
Race & $4(14)$ \\
$\quad$ White & \\
Other & $93(309)$ \\
Prefer not to answer & $4(12)$ \\
Ethnicity & $3(10)$ \\
Not Hispanic or Latino & \\
Hispanic or Latino & \\
Prefer not to answer & \\
\hline Note: Not all participants answered each question.
\end{tabular}

dant questions, modifying the response scale, and adding open-ended questions.

The survey included six sections (see Appendix A): (a) demographic information (seven items); (b) items of importance to talk about with parents (ten items); (c) challenges related to counseling parents (six items); (d) confidence with counseling skills (seven items); (e) frequency of performing each skill (seven items); and (f) counseling training received in graduate school (two items). There were also four open-ended questions to explore importance, challenges, confidence, and other information about challenges and/or successes experienced by the audiologists. Audiologists reported their perceptions on 5-point Likert scales (importance [1 = not important to $5=$ extremely important]; challenges [ $1=$ not challenging to $5=$ extremely challenging $]$; confidence $[1=$ not confident to $5=$ extremely confident]; frequency of time spent $[1=$ not addressed to $5=$ $>75 \%]$ ). The items related to confidence with counseling behaviors were derived from evidence-based counseling behaviors used in intentional interviewing (Ivey et al, 2016).

\section{Analysis}

The survey data were analyzed using SPSS (v23) analysis software. Descriptive statistics were used to identify frequencies and variance of item responses. Item analyses of the four domains included in the survey (i.e., importance, challenges, confidence, and frequency of skill use), revealed good internal consistency: importance 
( $\mathrm{n}=347 ;$ items $=10 ;$ Cronbach's $\alpha=0.83)$; challenges $(\mathrm{n}$ $=337 ;$ items $=6$; Cronbach's $\alpha=0.78)$; confidence $(\mathrm{n}=$ 342 ; items $=7$; Cronbach's $\alpha=0.90$ ); and frequency of skill use $(\mathrm{n}=332$; items $=7$; Cronbach's $\alpha=0.92)$. Participants were grouped based on years of experience (i.e., $\leq 10, \geq 11$ ) and whether they had taken a counseling course in their graduate training program. Groupings were done for these two variables because more audiology training programs began including a counseling course in their curriculum with the transition from a masters to a clinical doctoral degree. Differences among groups for each domain were investigated using analysis of variance. Content analysis was completed for the open-ended questions to identify emergent themes. The number of participants who responded, the number of statements per question, and examples of main themes are provided for importance, challenges, and confidence in Appendix $\mathrm{B}$, and in Appendix $\mathrm{C}$ for successes and challenges shared.

\section{RESULTS}

\section{Importance}

Audiologists were asked to rate how important they feel it is to talk with parents about ten items (e.g., their [parents'] expectations and perceptions about hearing loss). For ease in observing trends, responses were combined for "not important and slightly important," and for "very important and extremely important" (see Table 2). Most audiologists ( $\geq 75 \%$ ) felt it was very or extremely important to talk with parents about nine of the ten items. For example, audiologists felt it was very or extremely important to talk with parents about their expectations (98\%), their perceptions about hearing loss (90\%), their network of support (83\%), and their internal challenges (75\%); fewer (47\%) felt it was very or extremely important to talk about technical information (e.g., hearing aid components).

\section{Counseling Challenges}

Audiologists were asked to report how much they feel six items present a challenge for them when counseling parents (e.g., having enough time to address emotional needs). For ease in observing trends, responses for "not challenging and somewhat challenging," and "very challenging and extremely challenging" were combined (see Table 3). Three-fourth of the audiologists reported experiencing a moderate challenge or greater in knowing how to assess the presence of psychosocial challenges and in having enough time to address emotional needs; $60 \%$ reported a moderate challenge or greater in knowing how to help parents overcome barriers to daily management. Fewer audiologists reported experiencing a moderate challenge or greater in knowing how to connect families to other families for support (43\%), helping parents gain confidence with skills (41\%), and assessing parents' understanding of technical information (43\%).

\section{Confidence}

Audiologists were asked to rate how confident they feel in their ability to perform seven counseling skills, such as talking with parents about their strong emotions (see Table 4). For ease in observing trends, responses for "not confident and somewhat confident," and "very confident and extremely confident" were combined. More than half of the audiologists felt very or extremely confident in guiding parents in the development of an action plan (62\%) and determining if parents have external barriers (60\%). For the remaining five skills, less than half of the audiologists were very or extremely confident: talk with parents about their strong emotions (49\%); guide parents to find their own solutions to external barriers (44\%); appropriately challenge parents' denial of hearing loss (41\%); determine if parent has internal barriers (38\%), and

Table 2. Audiologists' Perceptions of Importance

\begin{tabular}{|c|c|c|c|}
\hline \multirow[b]{2}{*}{ How important is it to talk with parents about... } & \multicolumn{3}{|c|}{$\%(n)$} \\
\hline & Not/Slightly & Moderately & Very/Extremely \\
\hline Their expectations (e.g., process, outcomes) & $<1(1)$ & $2(6)$ & $98(343)$ \\
\hline Overcoming barriers with daily management & $1(5)$ & $5(17)$ & $94(328)$ \\
\hline Learning new skills (e.g., checking hearing aid function) & $2(6)$ & $7(26)$ & $91(318)$ \\
\hline Their perceptions about hearing loss & $1(2)$ & $9(32)$ & $90(316)$ \\
\hline Their strong emotions when receiving difficult news (e.g., crying) & $3(12)$ & $11(37)$ & $86(301)$ \\
\hline Their network of support (e.g., spouse, family, and friend) & $3(9)$ & $14(50)$ & $83(290)$ \\
\hline Their interest in talking to others about similar experiences & $3(11)$ & $17(59)$ & $80(279)$ \\
\hline Their external challenges (e.g., lack of knowledge) & $5(17)$ & $19(65)$ & $76(268)$ \\
\hline Their internal challenges (e.g., depression, stress, and anxiety) & $5(18)$ & $20(71)$ & $75(261)$ \\
\hline Technical information (e.g., hearing aid components) & $14(49)$ & $39(135)$ & $47(165)$ \\
\hline
\end{tabular}


Table 3. Audiologists Perceived Challenges

\begin{tabular}{|c|c|c|c|}
\hline \multirow{2}{*}{$\begin{array}{l}\text { How much do you feel each item presents a challenge for you } \\
\text { when counseling parents? }\end{array}$} & \multicolumn{3}{|c|}{$\%(n)$} \\
\hline & Not/Somewhat & Moderately & Very/Extremely \\
\hline Knowing how to assess presence of psychosocial challenges & $25(86)$ & $36(123)$ & $39(134)$ \\
\hline Having enough time to address emotional needs & $25(83)$ & $37(124)$ & $39(135)$ \\
\hline Knowing how to help parents overcome barriers to daily management & $40(138)$ & $36(124)$ & $24(82)$ \\
\hline Knowing how to connect families to other families for support & $57(197)$ & $25(88)$ & $18(61)$ \\
\hline Knowing how to help parents gain confidence with skills & $59(204)$ & $28(95)$ & $13(46)$ \\
\hline Knowing how to assess parents' understanding to technical information & $57(198)$ & $34(117)$ & $9(31)$ \\
\hline
\end{tabular}

guide parents to find their own solutions to internal barriers $(28 \%)$.

\section{Frequency Performing Skills}

Audiologists were asked to approximate how often they perform each of the seven skills in their practice. Responses for "I do not address this" and " $1 \%$ to $25 \%$ of the time" were combined for ease in identifying trends (see Table 5). The results revealed extensive variability in use of the skills, and approximately one-third or less of the audiologists reported performing any of the skills $\geq 75 \%$ of the time. Guide parents in development of action plan to address barriers, was reported most frequently $(36 \%)$, and guide parents to find their own solutions to internal barriers, was reported least frequently $(9 \%)$ by the pediatric audiologists.

\section{Counseling Education}

Audiologists were asked to indicate where, within their graduate training, they received coursework specific to knowledge and skills for counseling. Responses revealed $6 \%(\mathrm{n}=20)$ had no training, 36\% $(\mathrm{n}=125)$ had counseling included in one to two audiology content courses (e.g., hearing aids), $22 \%(\mathrm{n}=74)$ had counseling included in several audiology content courses, and 36\% $(\mathrm{n}=123)$ had one or more courses specific to counseling in audiology.

Audiologists were also asked to report the extent of training they received related to counseling in their clinical practicum experiences. Responses revealed $16 \%$
( $\mathrm{n}=56$ ) received no counseling training during clinical supervision, $35 \%(\mathrm{n}=119)$ received counseling training from 1 to 2 clinical supervisors, $34 \%(\mathrm{n}=116)$ received counseling training from several clinical supervisors, and $15 \%(\mathrm{n}=50)$ received counseling training from all of their clinical supervisors.

\section{Factors Influencing Counseling}

Years practicing audiology (i.e., $\leq 10 ; \geq 11$ ) and taking a counseling course were explored to investigate their influence on audiologists' perceptions of importance, their challenges, confidence, and how often they use counseling skills. Effect size analyses using Cohen's $d$ indicated small to medium differences between the means for findings that were statistically significant (see below and Table 6). A Chi-Square Test of Independence was performed to examine the relationship between having taken a counseling course and years of experience. The relationship between these variables is significant, $\chi_{(1,342)}^{2}=7.117, p=0.008$, suggesting that audiologists working $\leq 10 \mathrm{yr}$ were statistically significantly more likely to have taken a counseling course than audiologists working $\geq 11 \mathrm{yr}$ ( $45 \%$ and $30 \%$ respectively).

\section{Years of Experience}

Analysis of variance showed no statistically significant effects for importance $F_{(1,346)}=0.423, p=0.516$, challenges $F_{(1,343)}=0.276, p=0.600$, or confidence $F_{(1,343)}=0.589, p=0.443$. There was a main effect of

Table 4. Audiologists' Perceived Confidence in Ability to Perform Skills

\begin{tabular}{|c|c|c|c|}
\hline \multirow{2}{*}{$\begin{array}{l}\text { Rate how confident are you in your ability to do each of the } \\
\text { following as of right now }\end{array}$} & \multicolumn{3}{|c|}{$\%(n)$} \\
\hline & Not/Somewhat & Moderately & Very/Extremely \\
\hline Guide parents in development of action plan to address barriers & $10(34)$ & $28(95)$ & $62(211)$ \\
\hline Determine if parent has external barriers (e.g., lack of knowledge) & $9(31)$ & $31(107)$ & $60(209)$ \\
\hline Talk with parent about their strong emotions (e.g., sadness, anger) & $17(58)$ & $34(119)$ & $49(170)$ \\
\hline Guide parents to find their own solutions to external barriers & $14(48)$ & $42(143)$ & $44(153)$ \\
\hline Appropriately challenge parents' denial of hearing loss & $22(77)$ & $37(127)$ & $41(143)$ \\
\hline Determine if parent has internal barriers (e.g., fears, thoughts) & $24(82)$ & $38(132)$ & $38(132)$ \\
\hline Guide parents to find their own solutions to internal barriers & $28(99)$ & $44(151)$ & $28(97)$ \\
\hline
\end{tabular}


Table 5. Frequency of Skill Use in Practice

\begin{tabular}{|c|c|c|c|c|}
\hline \multirow[b]{2}{*}{ Approximate how often you perform each skill in practice } & \multicolumn{4}{|c|}{$\%(n)$} \\
\hline & $\leq 25 \%$ & $26-50 \%$ & $51-75 \%$ & $\geq 75 \%$ \\
\hline Guide parents in development of action plan to address barriers & $21(69)$ & $21(70)$ & $22(74)$ & $36(122)$ \\
\hline Determine if parent has external barriers & $22(72)$ & $27(89)$ & $29(98)$ & $22(73)$ \\
\hline Guide parents to find their own solutions to external barriers & $28(90)$ & $29(98)$ & $26(88)$ & $17(58)$ \\
\hline Talk with parent about their strong emotions & $44(148)$ & $21(70)$ & $20(65)$ & $15(52)$ \\
\hline Appropriately challenge parents' denial of hearing loss & $41(138)$ & $23(75)$ & $23(78)$ & $13(45)$ \\
\hline Determine if parent has internal barriers & $39(130)$ & $30(101)$ & $21(69)$ & $10(35)$ \\
\hline Guide parents to find their own solutions to internal barriers & $40(134)$ & $29(96)$ & $22(74)$ & $9(31)$ \\
\hline
\end{tabular}

years practicing audiology on reported use of counseling skills, $F_{(1,331)}=5.428, p=0.020$; audiologists practicing $\leq 10 \mathrm{yr}$ reported using the counseling skills more often than audiologists practicing $\geq 11 \mathrm{yr}$.

\section{Counseling Course}

Analysis of variance showed no statistically significant effects for importance $F_{(1,338)}=0.762, p=0.383$ and challenges $F_{(1,337)}=0.000, p=0.999$. There were main effects of taking a counseling course on confidence
$F_{(1,338)}=10.379, p=0.001$ and reported time using counseling skills $F_{(1,330)}=12.145, p=0.001$; audiologists who had a counseling course reported more confidence and using counseling skills more often than audiologists who did not have a counseling course.

\section{DISCUSSION}

ounseling is an important element of pediatric audiology practice. Parents need support in recognizing

Table 6. Effect of Counseling Course and Years Practicing Audiology on Importance, Challenges, Confidence, and Frequency of Skill Use

\begin{tabular}{|c|c|c|c|c|c|}
\hline & $\mathrm{n}$ & $\mathrm{M}(\mathrm{SD})$ & $\mathrm{Cl}$ & $p$ & $d$ \\
\hline \multicolumn{6}{|l|}{ Importance } \\
\hline Counseling course & & & & 0.383 & 0.1 \\
\hline Course & 122 & $4.25(0.51)$ & $4.16-4.34$ & & \\
\hline NO course & 218 & $4.20(0.48)$ & $4.13-4.26$ & & \\
\hline Years practicing audiology & & & & 0.516 & 0.08 \\
\hline$\leq 10 \mathrm{yr}$ & 134 & $4.24(0.48)$ & $4.16-4.32$ & & \\
\hline$\geq 11 \mathrm{yr}$ & 214 & $4.20(0.49)$ & $4.14-4.27$ & & \\
\hline \multicolumn{6}{|l|}{ Confidence } \\
\hline Counseling Course & & & & $0.001^{*}$ & 0.37 \\
\hline Course & 122 & $3.53(0.71)$ & $3.40-3.66$ & & \\
\hline NO course & 217 & $3.26(0.75)$ & $3.16-3.36$ & & \\
\hline Years practicing audiology & & & & 0.443 & 0.09 \\
\hline$\leq 10 \mathrm{yr}$ & 132 & $3.31(0.72)$ & $3.19-3.44$ & & \\
\hline$\geq 11 \mathrm{yr}$ & 213 & $3.38(0.76)$ & $3.27-3.48$ & & \\
\hline \multicolumn{6}{|l|}{ Challenges } \\
\hline Counseling Course & & & & 0.999 & 0 \\
\hline Course & 122 & $2.71(0.74)$ & $2.58-2.84$ & & \\
\hline NO course & 217 & $2.71(0.69)$ & $2.62-2.80$ & & \\
\hline Years practicing audiology & & & & 0.6 & 0.06 \\
\hline$\leq 10 \mathrm{yr}$ & 132 & $2.74(0.66)$ & $2.63-2.85$ & & \\
\hline$\geq 11 \mathrm{yr}$ & 213 & $2.70(0.75)$ & $2.60-2.80$ & & \\
\hline \multicolumn{6}{|l|}{ Frequency of Skill Use } \\
\hline Counseling Course & & & & $0.001^{*}$ & 0.39 \\
\hline Course & 119 & $3.45(0.84)$ & $3.30-3.61$ & & \\
\hline NO course & 213 & $3.10(0.93)$ & $2.97-3.22$ & & \\
\hline Years practicing audiology & & & & $0.020^{*}$ & 0.26 \\
\hline$\leq 10 \mathrm{yr}$ & 129 & $3.37(0.87)$ & $3.22-3.52$ & & \\
\hline$\geq 11 \mathrm{yr}$ & 204 & $3.13(0.94)$ & $3.00-3.26$ & & \\
\hline
\end{tabular}

$\overline{\mathrm{Cl}}=$ confidence interval; SD = standard deviation.

* = statistical significance 
and addressing challenges that interfere with auditory intervention, including hearing aid use and management (Muñoz et al, 2015; 2016). The purpose of the current study was to better understand pediatric audiologists' perceptions, training, and confidence related to counseling. Responses to the survey came from pediatric audiologists working in a broad geographical area and with varying years of experience. Study limitations included use of a self-report measure, not asking for work setting, and not exploring depth of counseling coursework and clinical supervision. Results from this study provided new information about counseling skills of pediatric audiologists and important insights into opportunities to enhance counseling education in audiology. The pediatric audiologists in this study received minimal counseling training to learn skills. They also experienced challenges navigating conversations concerning clients' emotional needs and engaging in shared planning with their patients.

The study found audiologists believe counseling is important. Other studies have also queried audiologists about their perspective on counseling and communication with patients. For example, audiologists in Australia felt patient-centered care was an important characteristic of the patient-practitioner relationship (Laplante-Lévesque et al, 2014), and pediatric audiologists in the U.S. have reported wanting more counseling training (Meibos et al, 2016). It is interesting to note that audiologists in this study rated the importance of talking with parents about technical information lower than other emotionally-based aspects (e.g., challenges in hearing aid management and parents' strong emotions); however, studies have found audiologists focusing on technical content rather than emotionallybased concerns during appointments (Ekberg et al, 2014; Grenness et al, 2015b; Muñoz, Ong, et al, 2017).

Overall, audiologists reported experiencing relatively few challenges related to counseling in the present study; however, challenges related to addressing emotions were most frequently reported. Furthermore, audiologists reported infrequently using many counseling skills in practice that would encourage patient engagement and adherence (e.g., guide parent in development of an action plan to address barriers). Findings suggest that counseling training may be a factor influencing implementation of skills in practice; audiologists who had a counseling course reported using counseling skills more frequently than audiologists who did not have a course. A recent study revealed that not all graduate training programs include a course in counseling (Whicker et al, 2017). Furthermore, only half of the audiologists in this study reported receiving supervision related to counseling skill development, a critical element for skill acquisition from novice to mastery levels (ASHA, 2017). It is interesting to note that audiologists who had been practicing longer (i.e., $>11 \mathrm{yr}$ ) reported using counseling skills less than audiologists who had been working fewer years, suggesting that counseling skill implementation does not necessarily increase with time in the absence of explicit instruction.

Learning how to navigate conversations that are not technically-based may represent training gaps in audiology. For example, audiologists may be unaware of when patient concerns reflect an underlying challenge related to coping with their hearing loss. Lack of awareness is an issue that has been found to impact physicianpatient communication (Hall et al, 1999). Audiologists may feel uncomfortable addressing patients' emotionallybased issues. Audiologists have reported feeling uncertainty (Muñoz, Ong, et al, 2017) and this may result in responding to emotional concerns with technically-based information. Meibos et al (2016) found that only $42 \%$ of pediatric audiologists were confident in knowing what to do to address parent concerns when they arise in practice. The relationship audiologists build with parents, through intentional use of counseling skills, can influence the effectiveness of their conversations with parents about challenges they experience. Within a therapeutic relationship, parents will feel more comfortable sharing their underlying emotional concerns (e.g., fear of others knowing about their child's hearing loss) and exploring solutions. The audiologist's role is not to fix the problem or have the solution but rather to work with parents to help them identify barriers they are experiencing and to find and implement solutions.

Further research is needed to better understand factors that facilitate/impede audiologists' ability to consistently and effectively implement counseling skills and influences of counseling on patient outcomes. For example, findings from the following research questions would provide critical insights:

1. What are current models of graduate training for counseling in audiology, and how effective are they in supporting skill acquisition and implementation in practice?

2. What characteristics of supervision increase use of counseling skills, and how long is supervision needed for skills to be maintained?

3. What are audiologists' attitudes about their role in counseling, and does attitude influence counseling practices?

4. Does implementation of effective counseling take more time, or when patients concerns are addressed is time spent more efficiently?

5. How are audiologists setting agendas in appointments, and whose priorities are being addressed?

6. How are patient outcomes influenced by counseling in audiology?

Addressing counseling training gaps offers benefits to future audiologists and the patients they will serve. There is also a responsibility to address the needs of 
currently practicing audiologists through continuing education opportunities that support behavior change. In addition, clearer guidance for counseling education from audiology accrediting bodies would support a more systematic training implementation.

\section{CONCLUSION}

$\mathrm{C}$ ounseling in pediatric audiology is important for supporting parents in recognizing and addressing intervention challenges for their children who are deaf or hard of hearing. This study found pediatric audiologists believe counseling is important; however, they report variability in the use of counseling skills. Audiologists who had a counseling course reported higher levels of confidence and use of skills than audiologists who did not have a course. Audiology would benefit from future counseling research and a systematic approach to counseling instruction within graduate training programs and opportunities for continuing education.

\section{REFERENCES}

American Academy of Audiology. (2004) Scope of Practice. http:// www.audiology.org/publications-resources/document-library/scopepractice.

American Academy of Audiology. (2013) Clinical Practice Guidelines on Pediatric Amplification. http://audiologyweb.s3.amazonaws. com/migrated/PediatricAmplificationGuidelines.pdf_539975b3e7e9f1. 74471798.pdf.

American Speech-Language-Hearing Association. (2008) Guidelines for Audiologists Providing Informational and Adjustment Counseling to Families of Infants and Young Children with Hearing Loss Birth to 5 Years of Age. http://www.asha.org/policy/ GL2008-00289.

American Speech-Language-Hearing Association. (2012) 2012 Standards and Implementation Procedures for the Certificate of Clinical Competence in Audiology. http://www.asha.org/Certification/ 2012-Audiology-Certification-Standards/.

American Speech-Language-Hearing Association. (2017) Clinical Education and Supervision. http://www.asha.org/Practice-Portal/ Professional-Issues/Clinical-Education-and-Supervision/.

Clark JG, English KM. (2014) Counseling-Infused Audiologic Care. New York, NY: Pearson.

Ekberg K, Grenness C, Hickson L. (2014) Addressing patients' psychosocial concerns regarding hearing aids within audiology appointments for older adults. Am J Audiol 23(3):337-350.

Grenness C, Hickson L, Laplante-Lévesque A, Meyer C, Davidson B. (2015a) Communication patterns in audiologic rehabilitation history-taking: audiologists, patients, and their companions. Ear Hear 36(2):191-204.

Grenness C, Hickson L, Laplante-Lévesque A, Meyer C, Davidson B. (2015b) The nature of communication throughout diagnosis and management planning in initial audiologic rehabilitation consultations. J Am Acad Audiol 26(1):36-50.

Hall JA, Stein TS, Roter DL, Rieser N. (1999) Inaccuracies in physicians' perceptions of their patients. Med Care 37(11):1164-1168.

Institute of Medicine. (2001) Crossing the Quality Chasm: A New Health System for the 21st Century. Washington, DC: National Academy Press.

Ivey AE, Ivey MB, Zalaquett CP. (2016) Essentials of Intentional Interviewing: Counseling in a Multicultural World. 3rd ed. Boston, MA: Cengage Learning.

Laplante-Lévesque A, Hickson L, Grenness C. (2014) An Australian survey of audiologists' preferences for patient-centredness. Int $J$ Audiol 53(Suppl 1):S76-S82.

Meibos A, Muñoz K, White K, Preston E, Pitt C, Twohig M. (2016) Audiologist practices: parent hearing aid education and support. J Am Acad Audiol 27(4):324-332.

Muñoz K, Kibbe K, Preston E, Caballero A, Nelson L, White K, Twohig M. (2017) Paediatric hearing aid management: a demonstration project for using virtual visits to enhance parent support. Int J Audiol 56(2):77-84.

Muñoz K, Olson WA, Twohig MP, Preston E, Blaiser K, White KR. (2015) Pediatric hearing aid use: parent-reported challenges. Ear Hear 36(2):279-287.

Muñoz K, Ong C, Borrie S, Nelson LH, Twohig M. (2017) Audiologists' communica-tion behavior during hearing device management appointments. Int $J$ Audiol 26:1-9. [Epub ahead of print]

Muñoz K, Rusk SE, Nelson L, Preston E, White KR, Barrett TS, Twohig MP. (2016) Pediatric hearing aid management: parentreported needs for learning support. Ear Hear 37(6):703-709.

Stewart M, Brown JB, Weston WW. (1989) Patient-centered interviewing part III: five provocative questions. Can Fam Physician 35:159-161.

Stone JR, Olswang LB. (1989) The hidden challenge in counseling. ASHA 31(6-7):27-31.

Tomblin JB, Harrison M, Ambrose SE, Walker EA, Oleson JJ, Moeller MP. (2015) Language outcomes in young children with mild to severe hearing loss. Ear Hear 36(Suppl 1):76S-91S.

Walker EA, Spratford M, Moeller MP, Oleson J, Ou H, Roush P, Jacobs S. (2013) Predictors of hearing aid use time in children with mild-to-severe hearing loss. Lang Speech Hear Serv Sch 44(1): 73-88.

Whicker J, Muñoz K, Butcher G, Schultz J, Twohig M. (2017) Counseling training in AuD programs: a syllabi review. Hear $J$ 70:36-39. 


\section{APPENDIX A}

1. State where you provide services:

2. Your age: $\square$ Prefer not to answer

3. Years practicing audiology: 4. Gender: $\square \mathrm{M} \square \mathrm{F} \square$ Prefer not to answer

5. Approximate percent of your time spent providing pediatric audiology services in the past three mo:

$\square 0 \% \square<25 \% \square 25-50 \% \square>75 \%$

6. Race: $\square$ American Indian or Alaska Native $\square$ Asian $\square$ Black or African America

$\square$ Native Hawaiian or Other Pacific Islander $\square$ White $\square$ Other:

$\square$ Prefer not to answer

7. Ethnicity: $\square$ Hispanic or Latino $\square$ Not Hispanic or Latino $\square$ Prefer not to answer

8. Indicate how important you feel it is to talk with parents about each of the following items:

\begin{tabular}{|c|c|c|c|c|c|}
\hline How important is it to talk with parents about... & $\begin{array}{l}\text { Not } \\
\text { Important }\end{array}$ & $\begin{array}{l}\text { Slightly } \\
\text { Important }\end{array}$ & $\begin{array}{l}\text { Moderately } \\
\text { Important }\end{array}$ & $\begin{array}{c}\text { Very } \\
\text { Important }\end{array}$ & $\begin{array}{l}\text { Extremely } \\
\text { Important }\end{array}$ \\
\hline $\begin{array}{l}\text { a. their strong emotions when receiving difficult news (e.g., } \\
\text { crying) }\end{array}$ & 1 & 2 & 3 & 4 & 5 \\
\hline b. technical information (e.g., hearing aid components) & 1 & 2 & 3 & 4 & 5 \\
\hline c. learning new skills (e.g., checking hearing aid function) & 1 & 2 & 3 & 4 & 5 \\
\hline d. overcoming barriers with daily management & 1 & 2 & 3 & 4 & 5 \\
\hline e. their perceptions about hearing loss & 1 & 2 & 3 & 4 & 5 \\
\hline f. their expectations (e.g., outcomes, process) & 1 & 2 & 3 & 4 & 5 \\
\hline g. their network of support (e.g., spouse, family, friend) & 1 & 2 & 3 & 4 & 5 \\
\hline $\begin{array}{l}\text { h. their internal challenges (e.g., depression, stress, } \\
\text { anxiety) }\end{array}$ & 1 & 2 & 3 & 4 & 5 \\
\hline i. their interest in talking to others about similar experiences & 1 & 2 & 3 & 4 & 5 \\
\hline j. their external challenges (e.g., lack of knowledge) & 1 & 2 & 3 & 4 & 5 \\
\hline
\end{tabular}

9. What other aspects do you feel are important to talk about with parents?

10. Indicate how much you feel each item presents a challenge for you in counseling parents:

\begin{tabular}{|c|c|c|c|c|c|}
\hline & $\begin{array}{c}\text { Not } \\
\text { Challenging }\end{array}$ & $\begin{array}{l}\text { Somewhat } \\
\text { Challenging }\end{array}$ & $\begin{array}{l}\text { Moderately } \\
\text { Challenging }\end{array}$ & $\begin{array}{c}\text { Very } \\
\text { Challenging }\end{array}$ & $\begin{array}{l}\text { Extremely } \\
\text { Challenging }\end{array}$ \\
\hline $\begin{array}{l}\text { a. having enough time to address emotional } \\
\text { needs }\end{array}$ & 1 & 2 & 3 & 4 & 5 \\
\hline \multicolumn{6}{|l|}{ Knowing how to... } \\
\hline b. connect families to other families for support & 1 & 2 & 3 & 4 & 5 \\
\hline $\begin{array}{l}\text { c. assess parents' understanding of technical } \\
\text { information }\end{array}$ & 1 & 2 & 3 & 4 & 5 \\
\hline d. help parents gain confidence with skills & 1 & 2 & 3 & 4 & 5 \\
\hline $\begin{array}{l}\text { e. assess the presence of psychosocial } \\
\text { challenges }\end{array}$ & 1 & 2 & 3 & 4 & 5 \\
\hline $\begin{array}{l}\text { f. help parents overcome barriers with daily } \\
\text { management }\end{array}$ & 1 & 2 & 3 & 4 & 5 \\
\hline
\end{tabular}

\section{What other aspects do you feel are challenging when talking with parents?}


12. For each skill, rate how confident you are in your ability to do each one as of right now.

\begin{tabular}{|c|c|c|c|c|c|}
\hline & Not Confident & $\begin{array}{l}\text { Somewhat } \\
\text { Confident }\end{array}$ & $\begin{array}{c}\text { Moderately } \\
\text { Confident }\end{array}$ & $\begin{array}{c}\text { Very } \\
\text { Confident }\end{array}$ & $\begin{array}{l}\text { Extremely } \\
\text { Confident }\end{array}$ \\
\hline a. Talk with parent about their strong emotion (e.g., sadness, anger) & 1 & 2 & 3 & 4 & 5 \\
\hline b. Appropriately challenge parent's denial of hearing loss & 1 & 2 & 3 & 4 & 5 \\
\hline c. Assess parent's external barriers (e.g., lack of knowledge) & 1 & 2 & 3 & 4 & 5 \\
\hline $\begin{array}{l}\text { d. Structure conversation to help parent determine how to address } \\
\text { external barriers }\end{array}$ & 1 & 2 & 3 & 4 & 5 \\
\hline e. Assess parent's internal barriers (e.g., fears, thoughts) & 1 & 2 & 3 & 4 & 5 \\
\hline $\begin{array}{l}\text { f. Structure conversation to help parent determine how to address } \\
\text { internal barriers }\end{array}$ & 1 & 2 & 3 & 4 & 5 \\
\hline $\begin{array}{l}\text { g. Structure conversation to guide development of mutually agreed } \\
\text { upon action plan }\end{array}$ & 1 & 2 & 3 & 4 & 5 \\
\hline
\end{tabular}

13. What other skills do you feel are confident in performing as of right now?

14. For each skill, approximate how often you perform each in practice:

\begin{tabular}{|c|c|c|c|c|c|}
\hline & $0 \%$ & $0-25 \%$ & $26-50 \%$ & $51-75 \%$ & $>75 \%$ \\
\hline a. Talk with parent about their strong emotion (e.g., sadness, anger) & 1 & 2 & 3 & 4 & 5 \\
\hline b. Appropriately challenge parent's denial of hearing loss & 1 & 2 & 3 & 4 & 5 \\
\hline c. Assess parent's external barriers (e.g., lack of knowledge) & 1 & 2 & 3 & 4 & 5 \\
\hline d. Structure conversation to help parent determine how to address external barriers & 1 & 2 & 3 & 4 & 5 \\
\hline e. Assess parent's internal barriers (e.g., fears, thoughts) & 1 & 2 & 3 & 4 & 5 \\
\hline f. Structure conversation to help parent determine how to address internal barriers & 1 & 2 & 3 & 4 & 5 \\
\hline g. Structure conversation to guide development of mutually agreed upon action plan & 1 & 2 & 3 & 4 & 5 \\
\hline
\end{tabular}

15. Indicate where you received training specific to knowledge and skills for counseling through academic coursework in your audiology graduate training program (circle number):

\begin{tabular}{llcc}
\hline 1 & 2 & 3 & 4 \\
\hline $\begin{array}{l}\text { No training } \\
\text { received }\end{array}$ & $\begin{array}{c}\text { Included 1-2 audiology content courses } \\
\text { (e.g., hearing aids) }\end{array}$ & $\begin{array}{c}\text { Included in several audiology } \\
\text { content courses }\end{array}$ & $\begin{array}{c}\text { One or more courses specific to } \\
\text { counseling in audiology }\end{array}$ \\
\hline
\end{tabular}

16. Indicate how often training specific to counseling techniques was provided in clinical practicum during your audiology graduate training program (circle number):

\begin{tabular}{lccc}
\hline 1 & 2 & 3 & 4 \\
\hline No training received & $\begin{array}{c}\text { Training from 1 to 2 } \\
\text { clinical supervisors }\end{array}$ & $\begin{array}{c}\text { Training from several } \\
\text { clinical supervisors }\end{array}$ & $\begin{array}{c}\text { Training from all clinical } \\
\text { supervisors }\end{array}$ \\
\hline
\end{tabular}

17. Please provide any additional comments that you feel would help us understand challenges and successes you have experienced related to counseling in your practice: 


\section{APPENDIX B}

\section{Audiologists' Responses to Open Questions for Importance, Challenges, and Confidence}

\begin{tabular}{lc}
\hline Responses \% $(\mathrm{n})$ & Themes \% (n) \\
\hline Importance & Parent learning/expectations \\
$51 \%(178)$ & $45(113)$
\end{tabular}

Child's education 11 (28)

Resources 9 (22)

Parent/child wellbeing 6 (15)

Responsiveness to parents 6 (15)

Challenges 41\%(144) Teaching parents 29 (55)

Parent-professional relationship 23 (44)

Parents' internal challenges 19 (37)

Culture/language barriers 10 (19)

Confidence 24 (84) Relationship building 39 (36)

Technical information 30 (28)

Resources 18 (16)
Quotes

We talk a lot about development expectations (what kids do when), how hearing can affect that. How children learn language and how hearing loss can change how kids learn (language for young ones and reading, math, grammar, etc. for older).

Understanding how hearing loss will affect communication/ speech abilities of their child as many did not initially see the connection.

Educational accommodations, FM systems, and navigating IEP process.

Direction to resources for parent support. Direction to educational support.

Discussing the child's awareness of his/her hearing loss; the child's internal challenges and perception. Making parents understand the child's self-esteem is gained from the reflection the parents give him/her.

Reassure the parents that they are in control of the decisions related to their child's care. I make sure that parents know my job is to provide them with unbiased options currently available and supported by research-based best practice. Their job is to love their child and make the decision they feel is best for their child and their family.

Getting them to look forward to the future and having them understand the value of buy in to help with their child's success.

Helping parents understand the importance of consistent HA use.

Teaching parents to confidently explain their child's hearing loss and necessity of using hearing aids to family and caretakers

Hearing what they are saying under/behind their words. Carefully choosing words I use

Developing a rapport to facilitate honest communication discussion of families' goals and challenges.

Discussing "what to do" on a practical level can be challenging if they are struggling to deal with hearing loss emotionally.

Encouraging open dialogue about the challenges they face (rather than continuing a relationship in which they feel they need to tell me what they are "supposed" to say).

Overcoming language and cultural barriers-trying to be respectful of cultural differences while trying to secure patient to the best of my abilities.

Being able to 'listen' to parents on their concerns for their child other than jumping in with review of all aspects of testing or other technical info

Building rapport and trust. Supporting parental confidence.

Explaining audiology-related information in laymen's terms and in a way that makes it easier for nonaudiologists to understand

Guiding them toward available resources such as early intervention and parent support.

Note: Number of items listed in each category varied (Importance 250; challenges 190; confidence 92); many audiologists listed more than one item. FM = frequency modulated; IEP = individual education plan; HA = hearing aid. 
Counseling in Pediatric Audiology/Muñoz et al

\section{APPENDIX C}

\section{Audiologists' Responses to Open Question for Their Successes and Challenges}

\begin{tabular}{|c|c|c|}
\hline Responses \% (n) & Main Themes & Quotes \\
\hline \multirow[t]{10}{*}{ Successes 28 (98) } & \multirow[t]{5}{*}{ Education 51 (50) } & $\begin{array}{l}\text { My graduate program has a strong emphasis on counseling (particularly for } \\
\text { pediatrics). }\end{array}$ \\
\hline & & $\begin{array}{l}\text { I had several fabulous supervisors and mentors who I have I learned from over } \\
\text { the years. }\end{array}$ \\
\hline & & $\begin{array}{l}\text { Once in practice, I attended numerous professional workshops on counseling } \\
\text { as it related to our field. I continue to obtain CEUs in this area. }\end{array}$ \\
\hline & & I have sought out specific counseling workshops for myself. \\
\hline & & $\begin{array}{l}\text { It was also extremely helpful watching skilled pediatric audiologists counsel } \\
\text { expertly, then incorporate their model into my work. }\end{array}$ \\
\hline & Hands-on experience 18 (18) & $\begin{array}{l}\text { Much of my counseling technique has come through years of experience. } \\
\text { I think comfort in counseling skills has grown the more I do it. }\end{array}$ \\
\hline & Rapport building 10 (10) & $\begin{array}{l}\text { Getting to know the family on a personal but professional level helps to } \\
\text { understand barriers that might be present at home/school that the parent } \\
\text { may not volunteer. Make both the child and parent feel comfortable with you } \\
\text { and confident in your skills as an audiologist. }\end{array}$ \\
\hline & Collaboration 9 (9) & $\begin{array}{l}\text { It is helpful to work closely with teachers and early intervention specialists. It is } \\
\text { also crucial that ever member of the child's support team buy into the } \\
\text { necessity of early intervention and full time use of their hearing equipment. }\end{array}$ \\
\hline & & $\begin{array}{l}\text { I work with a team of professionals who assist with the families I work with and } \\
\text { include social worker, translators, OT, PT, and SLPs. The beauty of this is } \\
\text { that all these individuals help with different situations that occur for families. }\end{array}$ \\
\hline & & Most counseling techniques were learned through practice and experience. \\
\hline \multirow[t]{6}{*}{ Challenges 21 (73) } & \multirow[t]{4}{*}{ Education 40 (29) } & $\begin{array}{l}\text { I don't feel our programs give audiologist enough training in this area. } \\
\text { I think this is an area that needs significantly more attention within our field, } \\
\text { especially for pediatric audiologists. }\end{array}$ \\
\hline & & No training received except information in aural rehab. \\
\hline & & $\begin{array}{l}\text { I remember our counseling training focused on body language, reading the } \\
\text { patient, but more about keeping our own body as an open listener, } \\
\text { supportive. I don't really remember talking about the emotions and how to } \\
\text { specifically address them other than the importance of asking how they are } \\
\text { doing... this said as I reflect on it, I realize I often jump into the purpose of the } \\
\text { visit, asking how the child is doing.. not really how they are feeling. }\end{array}$ \\
\hline & & $\begin{array}{l}\text { Need hands-on training. I have to take an online course but in the end, they } \\
\text { are not helpful without hands-on practice, role-play. Studying how to } \\
\text { counsel on paper does not help "in the moment." Audiologists who are } \\
\text { already in the field need expert counseling trainer to come on site for full day } \\
\text { workshops to get us up to speed. We all know we need to add counseling } \\
\text { courses to our AuD programs, but we also need a way to help those of us } \\
\text { already in the field. }\end{array}$ \\
\hline & Emotions 16 (12) & $\begin{array}{l}\text { It is challenging when a parent doesn't want to contribute to the conversation. } \\
\text { I thought l'd become better in dealing with denial but I still find it a struggle to } \\
\text { help that grieving family. }\end{array}$ \\
\hline & Time 11 (8) & $\begin{array}{l}\text { Not enough time to counsel! I have such a busy schedule there is a great deal } \\
\text { of pressure on me to perform quickly. }\end{array}$ \\
\hline
\end{tabular}

$\overline{\mathrm{CEU}}=$ continuing education unit; OT = occupational therapist; PT = physical therapist; SLP = speech-language pathologist. 